\title{
Addressing the Challenges and Cost of Health Care for At-Risk Children in Roanoke, Virginia, USA
}

\author{
Robin Haldiman ${ }^{1}$, Kerry J. Redican ${ }^{2, *}$, Kathy Hosig ${ }^{2}$, Kirby Deater-Deckard ${ }^{3}$ \\ ${ }^{1}$ CEO - Child Health Investment Partnership, 1201 Third Street SW, Roanoke, Virginia \\ ${ }^{2}$ Department of Population Health Sciences, Virginia Tech, Blacksburg, Virginia \\ ${ }^{3}$ Department of Psychology, Virginia Tech, Blacksburg, Virginia \\ *Corresponding author: kredican@vt.edu
}

Received January 24, 2014; Revised February 28, 2014; Accepted March 06, 2014

\begin{abstract}
The Child Health Investment Partnership of the Roanoke Valley (CHIP-RV), Virginia, USA, has been helping at risk children and families for the past 24 years. CHIP-RV began as a grassroots effort involving local pediatricians, social service agencies, and the public health department. Working together these professionals have developed and implemented a comprehensive program that provides for health care coordination, family strengthening services, and mental health services all directed at the mission of promoting health of medically underserved children within the greater Roanoke Valley. CHIP services are directed at low-income pregnant women and children from birth to kindergarten entry. Services include home visits with an RN, medical records reviews, inhome comprehensive assessments, health education, preparation for kindergarten, support for management of difficult behaviors, skill development, home and child safety, dental varnish application, and transportation to health and social services. Evaluations of the CHIP-RV model has shown CHIP-RV to be successful at meeting selected health and social needs of at-risk children and families. It is a model that should successfully interface with the Affordable Care Act as well as private/public efforts to reduce the cost of health care, help families to utilize the health care system and keep children well.
\end{abstract}

Keywords: Child Health, Medicaid, CHIP, at-risk children

Cite This Article: Robin Haldiman, Kerry J. Redican, Kathy Hosig, and Kirby Deater-Deckard, “Addressing the Challenges and Cost of Health Care for At-Risk Children in Roanoke, Virginia, USA.” American Journal of Medical Sciences and Medicine, vol. 2, no. 2 (2014): 29-36. doi: 10.12691/ajmsm-2-2-1.

\section{Introduction}

Providing an option for children from poor families to receive medical care has always been an important State and Federal issue in the United States. With the passage of Medicaid (Title XVIII and Title XIX) of the Social Security Act in 1965, the Federal and State governments became partners in providing a structure whereby poor children can receive medical care. This partnership came in the form of a program driven by both Federal dollars and a State match of funding. Many different events have continued to shape Medicaid. In 1967 an Early and Periodic Screening, Diagnosis, and Treatment (EPSDT) benefit was added for all Medicaid children under 21 years of age. It was 23 years after the passage of Medicaid that coverage of pregnant women and children under age 6 was mandated and the guidelines increased to 133 percent of the Federal Poverty Level (FPL). In 1990 coverage of children age 6-18 under 100\% FPL was established. The State Children's Health Insurance Program (SCHIP) was created in 1997 as a part of the Balanced Budget Act of 1997 and in addition to integrating more managed care into Medicaid created spending controls to slow the rate of growth in health care costs.
Medicaid is a highly political program, not because the public does not value providing access to medical care for poor children, but because that care is expensive and has strong impact on Federal and State budgets. In response to increasing Medicaid costs, states continually are looking at new and innovative ways to provide not just health care to poor children, but a variety of important services to the family at the same time.

Virginia, like all states, has grappled with increasing health care costs associated with Medicaid. The number of poor children receiving Medicaid and the money spent is staggering both in Virginia and the United States. According to the Kaiser Family Foundation State Health Facts and the Uninsured [1] Virginia has 1,027,075 of its total population covered by Medicaid and accounts for $1.5 \%$ total US population on Medicaid $(65,989,147)$. The percentage of residents below 133\% of the Federal Poverty Level and the amount of State and Federal money spent on Medicaid is continually increasing and as such becoming more and more political.

It is important to note that even though Medicaid has been implemented with good intentions it has not always helped the people it was designed to help - especially children. More specifically, Medicaid does provide access to medical care but physicians do not have to accept Medicaid insurance, leaving Medicaid insured patients 
without continuity of care and as result too much reliance on emergency rooms to deliver health care, especially primary health care. Further, children not having access to receiving primary care can be at risk of undetected and untreated physical, mental and social problems, including developmental delays, growth problems, asthma and emotional problems. Children from low income, uninsured families in Roanoke, Virginia, were no exception to the problems with Medicaid. To that end, an innovative program began, at the grassroots level in Southwest Virginia in 1989.

One Roanoke, Virginia pediatrician, Dr. Douglas Pierce observed these problems and wanted to be part of the solution His vision was the beginning of a partnership between physicians, families, dentists, and health and social service agencies to help children from low income families. This partnership matriculated into a formal agency called the Child Health Investment Partnership or CHIP which began in Roanoke, Virginia in 1988, enrolling the first child in 1989.

\section{Purpose}

The purpose of this article is to describe the evolution of the Child Health Investment Partnership and how this innovative program addresses the challenges and costs of health care for at-risk children through a combination of clinical and educational services.

\section{Child Health Investment Partnership of Roanoke Valley (CHIP-RV)}

In 1988, Dr. Pierce contacted Cabell Brand, a Roanoke, Virginia community leader, who was on the State Board of Health, and was Chair of the Board of Roanoke's Community action agency, Total Action Against Poverty (TAP). Dr. Pierce and Mr. Brand realized that if an innovative solution was to be achieved, all members of the medical/health/public health and social services teams needed to work together, and that the care delivered to the children enrolled in Medicaid must be coordinated. Physicians, dentists, social workers, health department personnel including public health nurses, and others needed to support a change in the way health care was delivered to children enrolled in Medicaid. During 1988, Dr. Pierce and Mr. Brand continued to recruit opinion leaders from health and social service segments of the community to participate in this approach. Early on health and social service agencies liked the idea and supported CHIP with human resources. Getting key health and social service professionals' support was effectively done and some funding sources identified to pilot the approach before trying to procure major funding.

Some initial funding was passed through to CHIP from the local health department from a Maternal and Child Health Block Grant through the Virginia Department of Health. Nurses were supported through this grant to monitor well child visits and improve immunization rates.

In cooperation with a physician group, the Roanoke Health Department and the resources of Total Action against Poverty and the block grant, 100 children were enrolled in 1989. In CHIP's infancy, CHIP public health nurses were employed by the health department and family intervention specialists through TAP. Participating community physicians provided a medical home for the children, rendering preventive and sick care, seven days a week, 24 hours per day. Participating dentists provided dental care, sealants and oral health education. The nurses coordinated the care with participating providers and created a health plan for each family, while the family intervention specialists helped families manage crisis situations that could result in poor health outcomes for the child and referred families to community resources for assistance and education.

Having established a successful CHIP pilot with the $\mathrm{MCH}$ block grant funds, stakeholders felt that it was the right time to try to procure major funding to expand and institutionalize the program.

TAP took the leadership role and received a one million dollar grant from the Kellogg Foundation to expand, and later replicate the program. The program, using both public and private resources was built around the four elements of community-oriented primary care: definition and characterization of the community, identification of the community's health problems, modification of health care programs in response to community health needs and monitoring of the impact of the program modification.

There was much excitement in the community and throughout the State about the CHIP model, and within two years Kellogg Foundation funded a replication project. Currently there are 7 other CHIP sites throughout the State of Virginia, which share the basis of home visitation; but offer different programs tailored to meet the needs of their individual communities. In 1997 The State Child Health Insurance Program was formed (SCHIP) to expand Medicaid to working families and pregnant women up to $200 \%$ of poverty. Much confusion was created with the acronym, particularly due to the parallels in population served through both programs. Though CHIP is a home visiting program for pregnant women and children up to age 6, and SCHIP is a Medicaid insurance program for pregnant women and children through age 18, much of the public continues to confuse the two programs.

CHIP-RV has continually evolved since its inception. In her final report of July, 2009 outlining a plan to assist CHIP-RV in becoming an evidence-based home-visiting program, Gomby states "CHIP possesses some strengths and unusual characteristics that set it apart from many other home visiting programs. For example, it has a comprehensive focus with especially strong roots in the health field. This is a contrast with several of the largest national home visiting programs: Healthy Families America, for example, emerged as a program to prevent child maltreatment, heavily influenced by theories from social work and psychology; Parents as Teachers, HIPPY, the Parent-Child Home Program, and Early Head Start were all probably influenced most by concepts from child development and early childhood education.” [2] (p4).

"The Nurse Family Partnership, whose home visitors are nurses, may be the most similar to CHIP in its focus on children's health (among other outcomes), but CHIP is differentiated from that and all the other major home visiting programs with its inclusion of the asthma case management and dental varnish components. Many home visiting programs have as a goal that children have a medical home and get their immunizations, but the programs typically do not go beyond that. With the 
addition of its asthma and dental components, which employ nurses to deliver care and/or partner closely with pediatricians and pediatric clinics in the community, CHIP staff serve as quasi-extensions of the health care system, which allows community pediatricians to deliver better care.” [2] (p4).

Some of CHIP's other components (e.g., mental health, transportation) also go beyond the case management, developmental screenings, and parent health education services that are often offered in many of the large national home visiting programs.

\section{How CHIP Works Today}

CHIP Mission: CHIP promotes the health of medically under-served children within the greater Roanoke Valley by ensuring comprehensive health care, strengthening families, and coordinating community resources in a public/private partnership

CHIP Vision: To enhance the quality of children's lives with emphasis on health, family and future.

Target Population: Low-income pregnant women and children from birth to kindergarten entry residing in Southwest Virginia cities of Roanoke and Salem and counties of Botetourt, Craig, and Roanoke. Low income is defined as having a gross annual income at or below 185\% of the Federal Poverty Level at enrollment and at or below 200\% of the Federal Poverty Level at recertification.

CORE Values: CHIP staff believes that interventions have the greatest impact when: they are provided through an interdisciplinary approach in partnership with parents, in the home-setting; initiated early in life; offered with dignity and respect in regards to cultures, beliefs, and parenting styles; and provided using evidence -based practices and established and emerging research.

In Gomby's report she further stated that “CHIP's staffing model also differs from that of many other home visiting programs. While many of the large home visiting models typically employ home visitors from a single service approach (e.g., nurses), CHIP employs staff with multiple backgrounds (e.g., nursing, early childhood education, social work/mental health), and then links those workers together into multidisciplinary teams that combine their joint expertise to serve individual families." [2](p5).

At enrollment, a comprehensive plan of care is designed for each enrolled child. This plan of care serves to both coordinate medical services and to maximize health outcomes. If a child does not have a designated pediatrician at enrollment, his/her CHIP nurse, in cooperation with the family, will locate a primary care provider, arrange an initial visit for the child, follow up with the family to ensure that the appointment was kept, and issue reminders for upcoming well-child and immunization visits.

In addition to locating and establishing a medical home for each enrolled child, nurses improve the health status of children and pregnant moms through medical case management and health education, serving as liaisons between parents and physicians, dentists, and other health care providers. CHIP requests medical records from each participating physician and dental office for enrolled children and pregnant mothers on an ongoing basis; nurses review the records to check that the child is up-to-date on his/her well-child visits and immunizations, that he/she has attained the appropriate height and weight for his/her age, and that assessments have been conducted to check for developmental delays. Nurses also review medical records for any recurring illnesses that might signal more serious health conditions and follow up with the child's pediatrician if any concerns are noted. Expectant mothers receive health education and support to understand and become accustomed to preventive care including regular prenatal care and specialist support for health risks such as high blood pressure and diabetes, and to continue with a medical home after the birth of their babies for postpartum check-ups, regular health exams, and the treatment of preexisting conditions.

When compliance rates for immunizations, well child check-ups and prenatal visits begin to decrease, the cause can almost always be related back to a child's or pregnant mother's insurance status. In an effort to keep children and pregnant moms current on their preventive health care visits, CHIP conducts monthly reviews of insurance status for all CHIP-enrolled children, verifying Medicaid recipient identification numbers and eligibility status through the Department of Medical Assistance (DMAS) online Automated Response System (ARS). If a child is found to be uninsured during this review, CHIP staff, in conjunction with local centers of eligibility determination, work with the family to re-establish coverage for their child(ren).

In September 2006, CHIP expanded the scope of its health care coordination services to provide structured medical case management for children birth to seven diagnosed with a respiratory disease or asthma that is poorly controlled. This component of the health care coordination program was labeled the Children's Pediatric Asthma Project. These services are designed to complement the care a child with asthma receives through his/her primary care provider or pulmonologist. Through monthly in-home evaluations of the child, medical records and individual case consultation with a child's primary care provider or pulmonologist, nurses obtain information about a child's asthma profile including environmental triggers, medications, history of attacks, frequency of emergency room visits and hospitalizations, and treatment recommendations.

Using this information, CHIP nurses instruct parents on how to make changes in the home to decrease environmental triggers, how to use and manage their child's medications (including proper dosage), and how to use spacers that make the most of asthma medications. Nurses also instruct parents with regards to managing an asthma attack including how to recognize the signs and symptoms of an impending attack, when to contact the child's primary care provider or asthma specialist, when to take the child in for evaluation, and when to take the child to the Emergency Room.

Together with parents and physicians, nurses support the development of an Asthma Action Plan that provides clear, easy-to-follow instructions on managing an asthma attack. This step-by-step approach helps parents and children break an attack down into stages with advice that makes the disease less intimidating for parents and less frightening for children. During 2009, there was a 91\% reduction in asthma-related events (hospitalizations and ER visits) from pre-enrollment levels in CHIP children 
who had been enrolled in asthma case management services for a year.

To round out health care coordination services offered to enrolled children, CHIP addresses the oral health of children through the in-home application of fluoride dental varnish, known as Begin With A Grin. The educational component (based on the Virginia Department of Health's Bright Smiles for Babies curriculum) provides parents with information on proper oral hygiene, nutrition and oral health literacy in an effort to reduce high risk behaviors (pre-chewing food, sharing utensils, and putting children to bed with sugary drinks) that lead to Early Childhood Caries.

In addition to educational support, nurses apply semiannual fluoride dental varnish to the teeth of CHIPenrolled children from tooth bud eruption to age 36 months who are not presently receiving varnish treatments through another health care provider. Fluoride varnishes are applied during a home visit and take between 1-4 minutes. Varnish treatments serve as vital preventive oral health care for the many CHIP-enrolled children at-risk for significant early tooth decay. In a Dental utilization study of Medicaid enrolled preschool children CHIP enrolled children were compared with children not enrolled in CHIP to measure Medicaid claims rates. When CHIP children are compared to just Medicaid enrolled children, the CHIP child is three times more likely to have one or more dental claims. This would imply that using a nurse home visiting model can introduce children and their families to prevention education, improved dental health literacy, and establishment of a dental home.

In addition to the health care component, when a child and his/her family enroll in CHIP, they receive support from one of CHIP's Family Case Managers (FCMs). FCMs provide services that work to strengthen the family unit, improve family self-sufficiency and support the development of confident parents who are able to provide safe and nurturing environments in which children can flourish. Family Strengthening Services include:

- Assisting families to set goals based on their family strengths.

- Educational and support services to assist parents in acquiring parenting skills. An evidence-based curriculum, Parents as Teachers is used with most first-time and teen parents to assist in acquiring knowledge of their child's development.

- Follow-up to ensure that necessary services are received by families to meet their needs.

- Transportation to WIC, counseling and family planning appointments.

- Community referral services to assist families in obtaining community resources

- Kindergarten preparation

In 2011 and 2012, CHIP received state grants that provide the opportunity for all home visiting staff to educate pregnant mothers and families about Shaken Baby Syndrome as well as risks of suffocation from co-sleeping. Pack n Play portable playards and blanket sleepers are available for infants from families with no resources for a crib.

To add to the multidisciplinary team approach, mental health case management services are available which focus on mothers with mental health issues(diagnosed or presenting) and children through age seven who are at risk for serious emotional disturbance, as well as children who are already showing signs of emotional or behavioral problems. Children are identified at intake or through a parental score on the Center for Epidemiological Studies Depression Scale and targeted for an observational home visit to determine need and eligibility for Mental Health services. The goal of CHIP's Mental Health program is to provide family focused strategies that promote optimal mental health for children who are at the highest risk for serious social-emotional disturbance and/or abuse and neglect.

Combined, this multi-pronged approach (nursing, family support and mental health services) address the many facets of early health care for low-income children and has significantly improved the health and developmental outcomes for CHIP-enrolled children.

\section{CHIP Staff}

The CHIP program began with only public health nurses, but it was soon evident that the issues within the family needed to be addressed before the health of the child could be affected. Family Intervention Specialists were hired (now called Family Case Managers), and a team comprised of one nurse and one family intervention specialist was formed. In an effort to strive for a more cost effective model, the team was changed to include two family intervention specialists to one public health nurse in the mid 90's. Five years later, the nursing shortage drove a change in the model once again; with the current configuration including one community health nurse, and three family case managers. A mental health case manager is also available to the family if the child qualifies for mental health case management services. The model is very affordable at $\$ 1,491$ per child served (FYE 6/30/12) or $(\$ 2,094$ per family) for a year compared to Nurse Family Partnership at $\$ 4,100$ average per family or Healthy Families at \$3,348. CHIP of Roanoke Valley currently has 4 full-time nurses and one part-time floating nurse who assists the team nurses in applying fluoride dental varnish, and case management for asthmatic and medically needy children and at-risk pregnant women. There are 12 Family Case managers and four mental health case managers. Full-time equivalent administrative staff includes a CEO, Director of Finance, Receptionist, Director of Nursing \& Training, Director of Family Support Services, Director of Mental Health Services, and Quality Assurance Coordinator and Annual Fund Coordinator. Part-time positions include Data Systems Manager (10 hours), Finance Assistant (30 hours), Executive Assistant (25 hours) and Team Secretary (20 hours). Grant Writing and Computer Report Programming are contracted out through independent contractors. This staffing configuration provides adequate support for families, excellent quality control and the ability to raise $\$ 630,000$ annually in private funds each year. CHIP-RV is also governed by a 28 member volunteer Board of Directors which includes high profile community leaders, scientists, community volunteers, and physicians.

\section{Evolution of CHIP-RV Services}

As CHIP became a more comprehensive organization, many new programs and services were added. Each arose from demonstrated need after numerous home visits by 
CHIP-RV staff, interactions with other health and social agencies, and Board of Director input. As mentioned earlier, family strengthening and support services were added in 1990, and then in 1999 mental health case management services were added in partnership with the local Community Services Board. As more and more Spanish speaking families enrolled, CHIP began hiring bilingual outreach workers (2003), who carry slightly smaller caseloads due to the increased needs of these nonEnglish speaking families to navigate multiple health care and social service systems. These bi-lingual outreach workers are trained and certified as medical interpreters. In 2006, CHIP-RV began its pediatric asthma case management, and now has each community health nurse trained and certified as an asthma educator. In the same year, CHIP trained all the nurses in fluoride varnish application, and began the Begin with a Grin fluoride varnish program. In 2007, all family case managers were trained in a kindergarten readiness curricula, based on Virginia Foundation Blocks. CHIP now uses the Parents as Teachers 3 to K curricula for kindergarten preparation.

\section{CHIP Long Term Outcomes}

All CHIP activities are related to the components of the CHIP model (Health Care Coordination and Supervision, Family Strengthening Services, and Mental Health Services) and form the basis for the short term outcomes. The long term outcomes (selected) for CHIP include: increasing access to needed health care services; improved health literacy; early detection and treatment of developmental delays; reduced infant and child mortality; disease management; family self-sufficiency; cost savings for school systems in special education and remediation; improved parenting capacity and school success.

\section{CHIP Evaluation}

CHIP-RV collects information on clients served and services delivered. Data are entered from multiple sources: medical records, home visit flow sheets, assessment tools and developmental screenings and analyses, according to goals established for each service or program by CHIPRV's Health Care Advisory Committee (HCAC). Data collected includes indicators of child and family wellbeing, progress toward goals, and compliance with recommended health care services and treatments. Data are analyzed on a quarterly basis for each outcome indicator and compared to its established goal. Any changes to the established goals are subject to approval after review by staff, HCAC and Board. CHIP-RV's data analysis process is unique when compared to other home visiting programs and insures the objectivity, integrity and consistency of the data across reporting years.

In her visit to CHIP-RV, Gomby noted that "CHIP also has established strong supervision and quality assurance practices that are not always present in other home visiting programs. Some of the national home visiting programs have uniform quality assurance practices, but communitybased home visiting programs have to develop their own approaches. The approach that CHIP uses could serve as a model for how community-based home visiting programs can monitor and improve the quality of their services.” [2] (p5).

CHIP-RV's data collection includes verifiable sources such as medical records received from the child's primary care providers and specialists, data gathered from area hospitals, and scoring on standardized developmental assessments (CESD, PSI, Bright Smiles for Babies, Ages and Stages 3, PAL's PreK) and screening tools as well as parent reports. Additional data safeguards include rigorous review of outcomes by an internal Outcomes Process Improvement Team and by CHIP-RV's HCAC which is comprised of pediatricians, health care executives and other pediatric specialists who also set the goals for the service objectives. CHIP children consistently outperform all available state and national benchmarks for health status, immunization compliance and access to healthcare services, even where state and national benchmarks include non-Medicaid populations in outcomes.

\begin{tabular}{|c|c|}
\hline CHIP Service Objective & $\begin{array}{l}2012 \text { Percentage Reached } \\
\text { and/or Number Referred }\end{array}$ \\
\hline \multicolumn{2}{|l|}{ CARE COORDINATION } \\
\hline Medical Home (At least one WCV/or scheduled appointment or $1^{\text {st }}$ due in future & $98 \%(n=1075)$ \\
\hline Dental Home (At least 1 DV/or scheduled appointment or $1^{\text {st }}$ due in future) & $75 \%(n=541)$ \\
\hline 95\% of newly enrolled CHIP children will be assessed for developmental delays within 3 months of enrollment & $90 \%(n=139)$ \\
\hline $\begin{array}{l}\text { All children determined at risk will be referred for intervention services as needed, unless child is already involved } \\
\text { in early intervention program }\end{array}$ & $\begin{array}{l}24 \text { Identified } \\
24 \text { Referred }\end{array}$ \\
\hline 95\% of families with enrolled children age birth to five will receive WIC services & $88 \%(\mathrm{n}=627)$ \\
\hline $60 \%$ of all enrolled will have an initial dental exam by age 3 & $52 \%(n=404)$ \\
\hline $50 \%$ of all children who use the emergency room will show a reduction in ER visits at annual recertification & $74 \%(n=136)$ \\
\hline $\begin{array}{l}90 \% \text { of served children turning } 2 \text { during the timeframe will have received the recommended number of } \\
\text { immunizations by age } 2\end{array}$ & $94 \%(n=191)$ \\
\hline 95\% of served children will have completed their immunization series by kindergarten entry or age 6 & $99 \%(n=85)$ \\
\hline $90 \%$ of served children will be up-to-date on recommended well-baby visits & $91 \%(n=1075)$ \\
\hline $60 \%$ of children age three and over have received regular dental care & $59 \%(n=541)$ \\
\hline
\end{tabular}


The specific service objectives for care coordination can be seen in Table 1.

Dental Varnish and Prenatal Care: Implementing dental varnish programs is an affordable way to prevent dental caries and can be administered by $\mathrm{RN}$ staff during the home visits. As can be seen in Table 2, the coverage of dental varnish is extremely high. Service objectives related to prenatal care (See Table 2) are more difficult to reach, especially the degree to which the client is up-todate on prenatal visits.

Table 2. Dental Varnish and Prenatal Care Service Objectives and Evaluation

\begin{tabular}{|c|c|}
\hline CHIP Service Objective & $\begin{array}{l}2012 \text { Percentage Re } \\
\text { and/or Number Ref }\end{array}$ \\
\hline \multicolumn{2}{|l|}{ DENTAL VARNISH } \\
\hline $\begin{array}{l}\text { Of CHIP enrolled children turning } 37 \text { months during the timeframe, } 90 \% \text { will receive at least one dental varnish } \\
\text { application before turning } 37 \text { months }\end{array}$ & $92 \%(n=145)$ \\
\hline Number of children receiving a dental varnish and number of varnishes & $\begin{array}{l}371 \text { children receive } \\
\text { varnishes }\end{array}$ \\
\hline $90 \%$ of families participating in the dental varnish program will receive in-home dental education & $100 \%(n=303)$ \\
\hline \multicolumn{2}{|l|}{ PRENATAL } \\
\hline $100 \%$ of CHIP enrolled pregnant mothers will be $90 \%$ UTD on prenatal visits & $68 \%(n=87)$ \\
\hline $20 \%$ of CHIP enrolled pregnant mothers who smoke, will quit smoking during pregnancy & $29 \%(n=17)$ \\
\hline $50 \%$ of CHIP enrolled postpartum mothers will breastfeed their babies for the first two months & $27 \%(n=48)$ \\
\hline $100 \%$ of CHIP enrolled pregnant mothers will be enrolled in WIC & $98 \%(n=92)$ \\
\hline $\begin{array}{l}90 \% \text { of CHIP pregnant teen mothers (under } 18 \text { years of age) without a high school dip } \\
\text { their education }\end{array}$ & $100 \%(n=3)$ \\
\hline
\end{tabular}

Family Strengthening: Activities related to family strengthening is a high priority for CHIP. Service objectives are focused on employment, education, school

readiness, and developmental milestones. Table 3 summarizes family strengthening service objectives and the degree of success in 2012 in reaching the objectives.

Table 3. Family Strengthening Service Objectives and Evaluation

FAMILY STRENGTHENING

Of parents unemployed or seeking employment at enrollment, 50\% will become employed by the two year anniversary in CHIP

Of parents with less than a high school education or GED at enrollment, 20\% will obtain their GED or high school diploma by two year anniversary in CHIP

$40 \%(n=70)$

Of parents who have obtained a high school diploma or GED, $10 \%$ will improve their education status through

vocational training, college or other institutions of higher education

$21 \%(n=84)$

? \% with GED or greater while participating in CHIP services

$26 \%(n=217)$

75\% of CHIP Children who are discharged for Kindergarten Entry by September 30 will have the required documentation to enter Kindergarten

75\% of CHIP children who took the 5 year ASQ during the timeframe will score at or above the standard

developmental milestones in each area as measured by the Ages and Stages Questionnaire

$96 \%(n=27)$

Mental Health: Improvement on measures such as Social Emotional Scores is difficult under any circumstances and CHIP has been successful in exceeding all service objectives with the exception of face to face contact. Because the mental health clients are often in the most crisis, substance abusing or highly transient, this objective is often the most difficult to achieve, even with multiple attempts.

Table 4. Mental Health Service Objectives and Evaluation

\section{MENTAL HEALTH}

90\% of Mental Health Case Managed enrolled families will have at least one successful monthly face to face contact

$63 \%(n=60)$

$67 \%(n=6)$

Social Emotional scores

$20 \%$ of parents will improve their scores on CESD after 12 months enrollment in CHIP

Mental Health Case Management

$46 \%(n=35)$

$20 \%$ of parents will improve their scores on enrollment in CHIP Mental Health Case Management

Pediatric Asthma Project: Asthma is a serious problem in children from low income families. The good news is with continuity of care asthma can be successfully managed. Ten CHIP service objectives are directed at assessment and management of asthma and are based upon the NIH guidelines with the desired symptom frequency. Table 5 summarizes the asthma service objective measures. While service objectives and associated percentages are relatively simple evaluations they do provide evidence that CHIP is successful in 
helping children and families in the core service areas, from actual medical records and are not self reports. particularly since the majority of the outcomes are taken

Table 5. Pediatric Service Objectives and Evaluation

\begin{tabular}{lc}
\hline \multicolumn{1}{c}{ CHIP Service Objective } & $\begin{array}{c}\text { 2012 Percentage Reached } \\
\text { and/or Number Referred }\end{array}$ \\
\hline PEDIATRIC ASTHMA PROJECT & 145 \\
Number of children receiving asthma case management services during timeframe & 62 \\
Number of children who received asthma case management services for at least one year & 420 assessments completed \\
with an average of 7 visits & $84 \%$ (n=420) \\
Assessments indicating that asthma symptoms are well controlled & $84 \%$ (n=420) \\
Assessments where minimal rescue inhaler use was reported & $81 \%(\mathrm{n}=420)$ \\
Assessments where minimal night awakening related to asthma symptoms was reported & $86 \%(\mathrm{n}=420)$ \\
Assessments where it was reported that the child experienced minimal disruption in activity & 18 \\
Number of children missing school due to asthma exacerbations & 12 \\
Number of parents missing work due to asthma exacerbations & 46 \\
Number of children reported to have an asthma action plan &
\end{tabular}

\section{CHIP Support}

CHIP-RV brings in around 1.7 million dollars in revenue each year. The largest portion (42\%) comes from its annual fund raising program which includes direct mail appeals to over 6,000 donors three times per year, two special signature events (TUG for TOTS and Breakfast with Santa), foundations, civic groups, churches and a few corporations. Two additional fund raising events are held on behalf of CHIP each year, raising approximately $\$ 40,000$ of the $\$ 630,000$ goal. The second largest source of revenue comes from third party reimbursements (33\%) through Medicaid managed care organizations for contracted case management services. CHIP-RV also receives a dwindling amount of Maternal Child Health funds passed through from their local health department, and applies for other State and Federal grants. Almost 7\% of its funding comes through United Way as an impact partner agency, another $6 \%$ through local governments (each locality that CHIP services provides financial support) and the remaining $12 \%(\$ 195,000)$ comes through a grant from CHIP of Virginia, the replication body which lobbies the General Assembly and provides funding for the CHIP sites across Virginia. CHIP of Virginia receives approximately 1.9 million annually from the State of Virginia, awarding 1.5 million back out to CHIP sites.

CHIP-RV uses over 3,600 hours per year of volunteer time annually with former clients and interested community members putting together annual events, donating books and other materials for the families, assisting with program operations, and raising funds for the organization. The volunteer commitment illustrates the depth of the roots that CHIP has within the community.

\section{Future of CHIP}

One of the overarching objectives of the Affordable Care Act is to provide Better Care, Better Health and Reduced Costs. These objectives line up with the CHIP program outcomes which improve prenatal and child health while decreasing their health care costs. Through team based care and proactive health promotion, CHIP's partnerships with existing managed care organizations position the program well to establish a data collection and evaluation plan that could demonstrate efficacy by analyzing claims data.

\section{Challenges for CHIP}

Funding is a continuous challenge and developing an evidence-based classification would allow CHIP to become eligible for additional grant funds without changing the characteristics of its program. As evidence is collected and cost savings are calculated, it is likely that local and state governments will increase their monetary support, and managed health care organizations will reimburse at a rate that could sustain and grow the program to serve more children. At 1,100 children served each year, CHIP-RV is considered a large home visiting program. However, over 6,000 children are eligible and could benefit from its services. Eighty six percent (86\%) of CHIP-RV expenses are staff who provide the services to families. It will be critical to expand staffing to accommodate additional families as more and more families fall into poverty and qualify for Medicaid.

\section{Funding, Science Based Evaluations/Research}

CHIP-RV has formed a Research and Evaluation Committee comprised of local pediatricians, researchers and university professors. This committee meets quarterly and discusses ways that CHIP can position itself for future studies. CHIP's first publication has been submitted to the Journal of Pediatrics for the fluoride varnish results. CHIP program directors have presented twice at the National Maternal Child Health Conference, (2010 \& 2013) in additional to being a panelist at the HRSA Healthy Tomorrows Conference in 2010. CHIP is currently participating in an evaluation with the school systems to match data of children discharged from CHIP at kindergarten entry with school data to assist in making data driven decisions about continuous quality improvement as well as the relationship between program 
participation in CHIP and school readiness. A small randomized control trial for an upcoming obesity prevention program began on July 1, 2013. CHIP has spent many hours writing a protocol manual, as well as a coding manual for the database in order to become "research ready". The CHIP Board of Directors is currently looking to find a major donor that would fund a research position for the next two years in order to establish their much needed evidence base.

\section{Implications for Practice}

Most CHIP services and activities involve increasing health literacy of parents and include strong health education components. Sound health education interventions are critical to strengthening families, coordinating community resources, and child health medical services such as vaccinations. For example, health education is strategic for implementing the Children's Pediatric Asthma Project and the focus on educating parents about environmental triggers, medications, treatment recommendations, and development of asthma action plans. There are CHIP or CHIP-like programs in many communities Health educators who are interested helping children from low income families have much to contribute to the effectiveness of these programs.

\section{References}

[1] Kaiser Family Foundation: State Health Facts. Virginia: Health Insurance Coverage of the Total Population, States (2010-2011) http://www.statehealthfacts.org. Published 2013. Accessed on April 10, 2013.

[2] Gomby DS. Building an Evidence-Based Home Visiting Program: A Plan for CHIP of the Roanoke Valley. Sunnyvale, CA: Denna Gomby Consulting: 2009. 